\title{
Review of grain threshing theory and technology
}

\author{
Jun $\mathrm{Fu}^{1,2,4}$, Zhi Chen ${ }^{2,3^{*}}$, Lujia Han ${ }^{4}$, Luquan Ren ${ }^{1}$ \\ (1. Key Laboratory of Bionic Engineering, Ministry of Education, Jilin University, Changchun 130022, China; \\ 2. College of Biological and Agricultural Engineering, Jilin University, Changchun 130022, China; \\ 3. China National Machinery Industry Corporation, Beijing 100080, China; \\ 4. College of Engineering, China Agricultural University, Beijing 100083, China)
}

\begin{abstract}
Threshing is the most important function of grain harvester. Grain loss and damage in harvesting are significantly related to threshing theory and technology. There are four kinds of threshing principles including impact, rubbing, combing and grinding. Four types of contact models between grain and threshing components have been constructed correspondently. Grain damage can be regarded as a function of peripheral velocity and contact pattern of impacting. Grain loss can be regarded as a function of contact pattern of rasp bars. Grain loss coming from cleaning and separation in the subsequent process of combing threshing was significantly decreased. Tangential and axial threshing technologies have been applied in grain threshing system widely. It showed that in the combined application, tangential rolls are used to accelerate grain flow, and axial rolls are used to increase threshing quality especially lower loss and damage. Conical concave may take the place of the traditional cylindrical one. With the development of sensor technology and communication technology, intelligent harvesting robot and automatic threshing system will be integrated together to improve grain quality and operation comfort.
\end{abstract}

Keywords: grain, threshing, threshing theory, threshing technology, harvester, grain loss

DOI: $10.25165 /$ j.ijabe. 20181103.3432

Citation: Fu J, Chen Z, Han L J, Ren L Q. Review of grain threshing theory and technology. Int J Agric \& Biol Eng, 2018; 11(3): 12-20.

\section{Introduction}

Rice and wheat are major grain crops in the world. The planting area of rice in China is about 30 million ha and its annual yield is more than 200 million $\mathrm{t}^{[2]}$. Almost half of the world population feed on rice ${ }^{[2]}$. Likewise, wheat is the highest yield food crop and ranks first among cereals ${ }^{[3]}$. Consequently, grain harvester is an important agriculture machinery that improves harvesting efficiency and reduces labor costs ${ }^{[4-7]}$. The typical kind of grain harvester is a combine which integrates the harvesting processes such as gathering, cutting, threshing, separation and cleaning, etc., especially threshing is its most important function ${ }^{[8]}$. Furthermore, grain loss and damage in harvesting are significantly affected by threshing performances ${ }^{[9-12]}$. Hence, many researchers put their efforts to investigate grain-threshing devices, and different kinds of grain threshers or threshing components have been developed since $1820 \mathrm{~s}^{[13-18]}$.

However, higher level of threshing theory and technology are still the unswerving pursuit, due to the fact that they always seriously affect grain loss and damage. Loss rate is a major parameter to evaluate the performance of grain threshing ${ }^{[19-23]}$. Dodds has reported that there are four resources of grain loss, namely, nature, cutting and rolling, pick-up, threshing and

\section{Received date: 2017-04-16 Accepted date: 2018-04-17}

Biographies: Jun Fu, PhD, Associate Professor, research interests: bionic threshing technology and equipment of grain, Email: fu_jun@jlu.edu.cn; Lujia Han, PhD, Professor, research interests: development and utilization of biomass resources, Email: hanlj@cau.edu.cn; Luquan Ren, Professor, Academician of Chinese Academy of Sciences, research interests: agricultural mechanization engineering, Email: lqren@jlu.edu.cn.

*Corresponding author: Zhi Chen, $\mathrm{PhD}$, Professor, research interests: grain harvesting technology and equipment. China National Machinery Industry Corporation, Beijing 100080, China. Tel: +86-10-82688715, Email: caamschen@126.com. separating ${ }^{[24]}$. Natural loss comes from weather conditions such as wind and rain ${ }^{[25]}$. Others are relevant to the mechanical performances of combine. As is known, the weather is uncontrollable. Therefore, reducing the mechanical loss may be a more practicable means to improve quality of grain threshing. Likewise, damage rate is another direct index of grain threshing which negatively affects the market value and storage ${ }^{[26-31]}$. Typical kinds of grain damage are mechanical damage and chemical damage. Mechanical grain damage is due to the impact of grain kernels and rigid surface of threshing unit of high relative speed $^{[32-35]}$. The method of high-speed digital imaging has been used to find the morphological and textural characteristics of three views of grain when grain kernels free fall and impact ${ }^{[36]}$. Chemical damage comes from a complex of fungi when grain is harvested during the rainy season ${ }^{[37-39]}$. Previous research indicates that if grain crops are harvested at physiological maturity and then dried artificially, the grain chemical damage could decrease to the minimum level ${ }^{[40-42]}$.

Many mechanical improvements have been made empirically to reduce the grain loss and damage. For instance, Ahmad et al. ${ }^{[43]}$ modified the designs of beater and beater drum of conventional wheat thresher. As a result, grain damage is reduced four times and grain-cleaning efficiency is improved from $97.44 \%$ to $98.18 \%$. In order to change the contact condition, Mesquita et al. ${ }^{[4]}$ installed nylon cords on the rotating shafts. The result indicates that threshing efficiency increased from $94.8 \%$ to $99 \%$, which was substantially higher than conventional threshing components. At the same time, seeds broken rate ranges from $0.6 \%$ to $0.3 \%$, which was also considerably lower than the conventional level $(8.4 \%)$. Another improvement of threshing component was made on the Thai-made combine ${ }^{[45]}$. A stripping rotor was used to take the place of cutter bar system. It consisted of eight rubber blades fixed on an octagonal drum, and each blade had 71 teeth. As the 
result showed that the rice loss rate was $4 \%$ in standing crop condition and 5.6\% in lodged crop condition, and the average percentage of crack grain was $1.6 \%$. Additionally, to optimize the performance of concave, which was the general threshing component in grain harvester, experiments were conducted based on different concave clearances and drum speeds ${ }^{[46]}$. It was found that grain damage decreased when the concave clearance increased from $29 \mathrm{~mm}$ to $35 \mathrm{~mm}$, while it increased when the drum speed ranged from $675 \mathrm{r} / \mathrm{min}$ to $875 \mathrm{r} / \mathrm{min}$. Although above empirical methods could reduce grain loss or damage to some extent, they are usually applied in specific conditions and partial grain crops.

This paper starts with a brief introduction of two main problems of grain threshing including grain loss and damage. Afterwards, four types of threshing principles were analyzed. In particular, four threshing contact models are established. Based on threshing theory, four threshing technologies are extended, and characteristics of typical threshing equipment are summarized. Finally, three development trends of grain threshing are discussed.

\section{Grain threshing principles}

There are four kinds of grain threshing principles including impact, rubbing, pre-cut combing and grinding ${ }^{[47-49]}$. Correspondently, four types of contact models between grain crops and threshing components are generated. Grain threshing performance such as loss and damage are significantly affected by contact pattern between grain crops and threshing components. Contact models are constructed based on geometric structures and mechanical motions of threshing devices. Force and motion are not only the two important parameters of contact models, but also the key influence factors of grain threshing performance such as loss and damage. So, contact models of grain threshing are summarized and analyzed in this paper.

\subsection{Impact threshing}

The contact model of impacting threshing is shown in Figure 1. Teeth such as spike teeth and bow teeth bolted on drum are the key threshing components of impacting threshing device. The threshing clearance spreads from the root of threshing tooth to the top of concave grate (Figure 1a). The primary energy used for threshing comes from impact contact between threshing teeth and grain ears (Figure 1b). When drum rotates, threshing teeth penetrate into grain crop mat in threshing clearance. Grain ears are impacted by high-speed threshing teeth with additional actions of compression, rubbing and combing ${ }^{[50-53]}$. Grain kernels are detached from stalks with acceleration resulted from impact. At the same time, grain crops mat is loosened by the penetrated threshing teeth. Consequently, grain kernels fall into the opening between neighbouring concave grates.

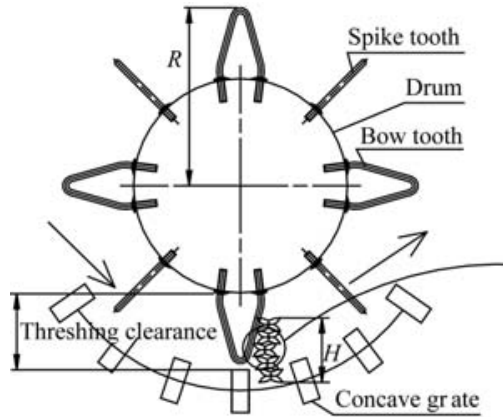

a. Impacting threshing device

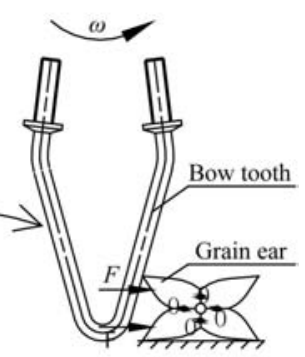

b. Impacting threshing contact
Figure 1 Contact model of impacting threshing
Previous investments have developed the contact model of impact threshing ${ }^{[54]}$. It is found that peripheral velocity of teeth, types of teeth and types of drum all have prominent effects on threshing efficiency and kernel surface quality ${ }^{[5-57]}$. Grain crops mass obtains impact force and sustains internal resistance among the mass flow and frictional resistance at concave. When the peripheral velocity of teeth is greater than the critical velocity of impact damage, the impact force plays an important role for grain damage ${ }^{[58]}$. Otherwise, the internal resistance and frictional resistance give rise to grain damage. Modification of the surface of threshing teeth could change the pattern of impact contact ${ }^{[59]}$. Therefore, grain damage can be regarded as a function of peripheral velocity and contact pattern.

\subsection{Rubbing threshing}

The contact model of rubbing threshing is shown in Figure 2. Normally, six or eight rasp bars are installed on a drum to form a threshing cylinder, and a concave of wrap angle of $110^{\circ}$ is underneath the cylinder (Figure 2a). A lot of ribs are distributed on the threshing contact surface of each rasp bar (Figure 2b), which increase the friction coefficient between rasp bar and grain ears ${ }^{[60-64]}$. Therefore, rasp bars are the key threshing components of rubbing threshing device. They are used most widely to form a threshing clearance, which spreads from the top of rasp bar to the top of concave grate, where grain ears are threshed under the influence of friction. The process of grain threshing could be identified as follows: grain kernels are detached from stalks usually by rubbing of rasp bars and concave grate, and then penetrate through the straw mat, lastly pass through the opening between neighbouring concave grates.

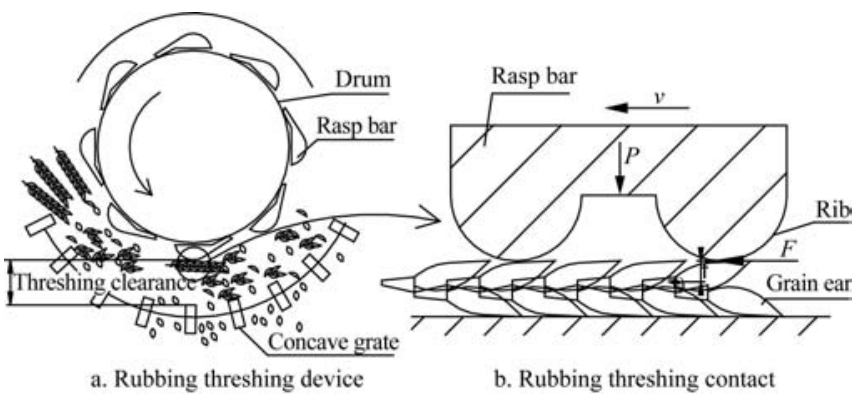

Figure 2 Contact model of rubbing threshing

Many efforts have been made to develop the contact model of rubbing threshing, which is important to analyze the principle of grain threshing ${ }^{[65-71]}$. Because grain kernels and straw have different coefficients of restitution, they are accelerated around the concave at different rates when energy is transmitted to them by rasp bars ${ }^{[72]}$. Under the combination of gravity and centrifugal force, grain kernels pass through straw mat and escape through concave opening. However, when the grain kernels contact with concave grate, bounce will generate and grain kernels will escape again or be expelled out with the straw. Consequently, grain loss in threshing is produced. Therefore, grain loss can be regarded as a function of contact pattern of rasp bars.

\subsection{Pre-cut combing threshing}

The contact model of pre-cut combing threshing is shown in Figure 3. Normally, eight or ten combing bars are installed on a drum to form a threshing cylinder. There is no concave in the pre-cut combing threshing device. However, an inlet is formed below the hood front. Only grain ears are contacted with combing bars through this inlet ${ }^{[73]}$ (Figure 3a). There is a V-type opening in the front of each combing tooth. When the combing bar moves from grain stem to grain ear, the combing tooth will contact with 
grain plant at the connection of stem and ear (Figure 3b), where there is a significant difference of cross sectional area ${ }^{[74]}$. Because the joint strength between kernels and ear axis is smaller than the tensile strength of stem, grain kernels are extruded at the threshing clearance successfully. Consequently, grain stems are left in the field.

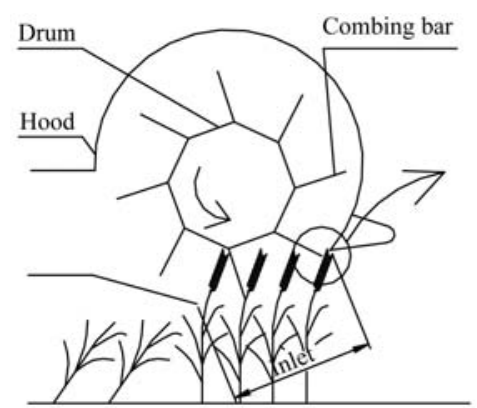

a. Pre-cut combing device

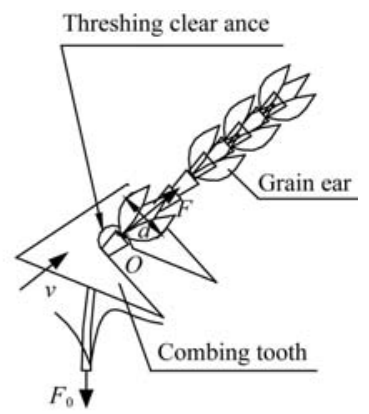

b. Pre-cut combing contact
Figure 3 Contact model of pre-cut combing threshing

Previous investigations have found that the spatter loss is the major form of grain loss in combing threshing. Although combing threshing is challenged mainly by grain spatter and crops lodging, some experiments have certified that the contact of combing threshing has contributed to separation ${ }^{[75]}$. Furthermore, only grain ears are contacted in the hood, and grain stems are entirely outside of threshing cylinder, there is little mixture of kernels and stems. Grain loss of cleaning and separation in the subsequent process is significantly decreased.

\subsection{Grinding threshing}

The contact model of grinding threshing is shown in Figure 4. A pile of grains is randomly laid on the road. Pressure roll such as rock roll or rubber tire grind the grains back and forth. Grains are contacted with road and roll simultaneously (Figure 4a). When grinding contact generates, grain ears are applied positive force and moment in axial and radial direction respectively (Figure 4b). In axial direction, grain ear twirls around node $O$ and rolls on the road. As a result, grain kernels are separated and detached from axis of grain ear.

Previous investigations have found that the moisture content of grain has significant impact on the contact performance of grinding threshing ${ }^{[76-82]}$. The higher the moisture content is, the more severe the damage to grain kernels in grinding threshing is. Furthermore, the threshing efficiency is lower because of lower rolling rate. So, grinding threshing is applied few in mechanical threshing.

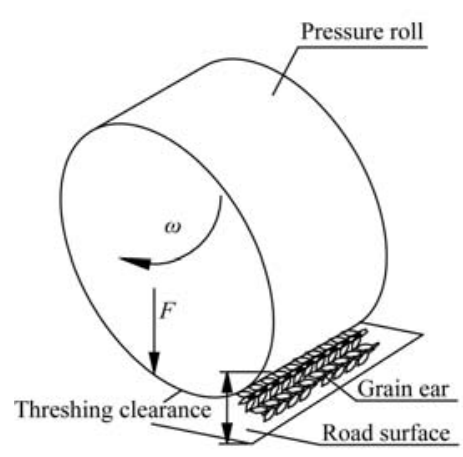

a. Grinding threshing device
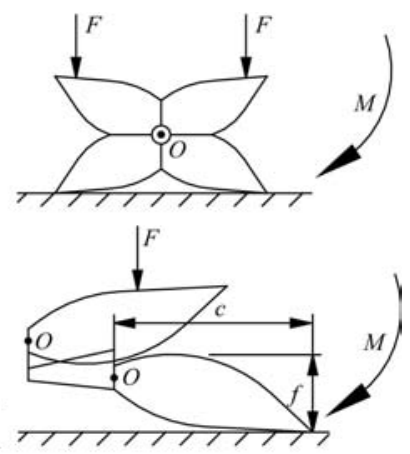

b. Grinding threshing contact
Figure 4 Contact model of grinding threshing

\section{Grain threshing technology and equipment}

Grain threshing technology and equipment are developed based on threshing principles. Axial-flow and tangential-flow are typical threshing technologies that are popular with enterprisers and farmers in the world. Furthermore, four-drum and APS threshing cylinders are developed based on them.

\subsection{Grain threshing technology}

Grain threshing technology has been developed since the first grain harvester was invented more than two hundred years ago. There are three kinds of classification methods about grain harvester.

\subsubsection{Primary threshing technology}

According to different mounting positions of threshing components, there are three primary threshing technologies including cross, longitudinal and vertical harvester respectively ${ }^{[83]}$. When threshing components are installed perpendicularly to straw flow, it is called cross-direction harvester. In the same way, when parallel to straw flow, it is called longitudinal-direction harvester. And when vertical to straw flow, it is called vertical-direction harvester. While according to the grains are whether whole fed into threshing cylinder, it can be classified into whole-feeding and half-feeding harvesters ${ }^{[84]}$. The third kind of classification of grain threshing technology is closely related to the structure of threshing component, which is widely used to analyze the performance of grain threshing. That is, according to the direction of the grain flow relative to the axis of the threshing unit, it could be classified into axial-flow and tangential-flow. These two kinds of harvesters were patented over two centuries ago. There are four common types of grain threshing by synthesizing the above three classifications, namely, cross-tangential flow (Figure 5), longitudinal-axial flow (Figure 6), vertical-axial flow (Figure 7) and pre-cut combing threshing harvesters (Figure 8).

\subsubsection{Cross-tangential threshing technology}

In the cross-tangential threshing technology, the threshing cylinder rotates with high speed (Figure 5). When a pile of grains pass through the drum quickly, spike teeth and bow teeth beat grain ears alternately. Detached grain kernels fly through concave, and run around a cross cylinder with only a tangential velocity. The rotate speed of this threshing cylinder ranges from $800 \mathrm{r} / \mathrm{min}$ to $1200 \mathrm{r} / \mathrm{min}^{[85-89]}$. In addition, the path of grain stalks is the internal surface of concave, which could reduce stalk blockages between drum and concave. However, when the moisture content of grain is higher, the connection force between kernels and axis of grain ear is bigger. Consequently, the detachment action of grain kernels will spend more time, and threshing efficiency will be reduced. In this case, higher rotate speed of threshing cylinder is needed. But the momentum and inertia force transferred to grain ears will be increased, which extremely raise the possibility of grain damage. Therefore, the cross-tangential threshing technology is usually applied as an assistant threshing device. For example, a cross-tangential threshing cylinder may be installed in the front of threshing system to enhance initial material feeding.

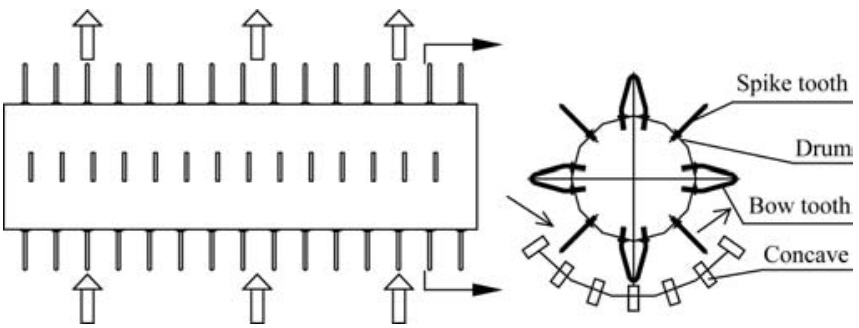

Figure 5 Cross-tangential threshing cylinder

\subsubsection{Longitudinal-axial threshing technology}

In the longitudinal-axial threshing technology, threshing teeth 
are installed on the drum uniformly in the cross section, and in spiral arrangement in axial direction. They make up the threshing cylinder. A hood with vanes is mounted above threshing cylinder, and the concave is below the threshing cylinder. Grain materials are mainly impacted and rubbed by threshing teeth and concave $^{[90,91]}$. At the same time, the vanes direct grain materials to pass through the threshing cylinder. Consequently, grain kernels are detached from grain ear axis and separated through concave. In addition, grain stalks are expelled from the threshing cylinder.

Based on the longitudinal-axial flow threshing technology, the detached kernels run around the longitudinal cylinder with a comprehensive velocity, which consists of axial and tangential velocity components. Because the axial velocity produces an additional distance along the rotary axis, grain kernels have adequate opportunities to detach from the stalks and to escape from the cylinder ${ }^{[92]}$.

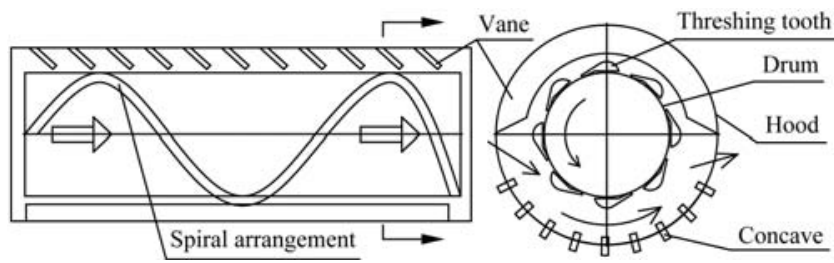

Figure 6 Longitudinal-axial threshing cylinder

\subsubsection{Vertical-axial threshing technology}

The vertical-axial flow threshing (VAFT) technology was invented by Ma J. in $1977^{[93]}$. He changed the conventional threshing process by adopting a vertical cylinder which had four kinds of threshing teeth such as blade feeding tooth, bow threshing tooth, U-type threshing tooth and straw through-out tooth ${ }^{[94]}$ (Figure 7). All the four types of teeth are installed on a vertical drum from bottom to up. And a $360^{\circ}$ circular concave positioned outside the threshing drum to produce twice area as large as the horizontal axial-flow with the same concave length. Consequently, the grain kernels have higher frequency of teeth impact to improve threshing efficiency.

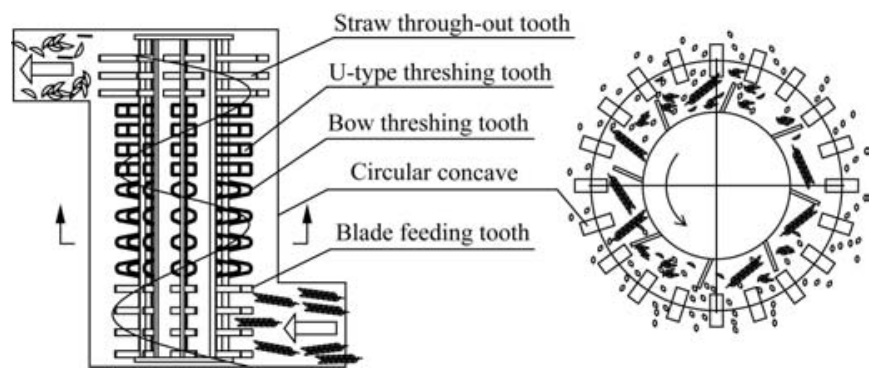

Figure 7 Vertical-axial threshing cylinder

In the vertical-axial threshing technology, grain materials are fed into threshing cylinder on the bottom, and directed spirally to the upside. Under the action of centrifugal force, grain kernels are thrown outside through the concave ${ }^{[95]}$. So the rotate speed of threshing teeth is high enough to enhance grain kernels to be threshed and detached.

3.1.5 Pre-cut combing threshing technology

The pre-cut combing threshing concept dates back to around 70AD in Roman and then developed in England, Australia, USA, Philippines and China. The typical pre-cut combing threshing harvester (Figure 8) was designed by the Silsoe Research Institute in UK in $1984^{[96]}$. In the pre-cut combing threshing technology, only grain ears are picked up into hood, and grain stalks still stand in the field ${ }^{[97]}$. So this threshing technology significantly reduces energy consumption. In addition, grain ears are combed by key hole-slotted combing tooth and grain kernels are detached from the straw simultaneously. Because grain ears and straws are harvested respectively, the processes of grain separation and cleaning would become simply and grain loss will be reduced.
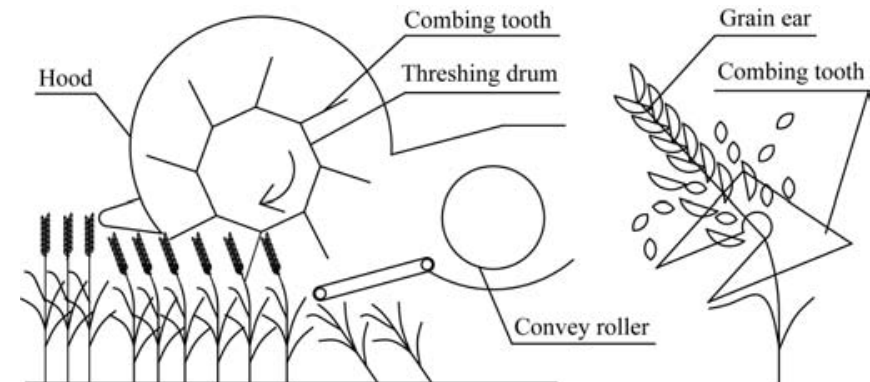

Figure 8 Pre-cut combing threshing harvester

\subsection{Grain threshing equipment}

Most combine production enterprise distribute in Europe and the United States as a result of the scaled agriculture production and the increase of labor cost. The German company Claas known around the world for their APS hybrid system dominates the European combine market. Agco, John Deere, Case IH and New Holland are the top four combine manufacturers in the United States whose productions are used more for large-scale harvesting operation.

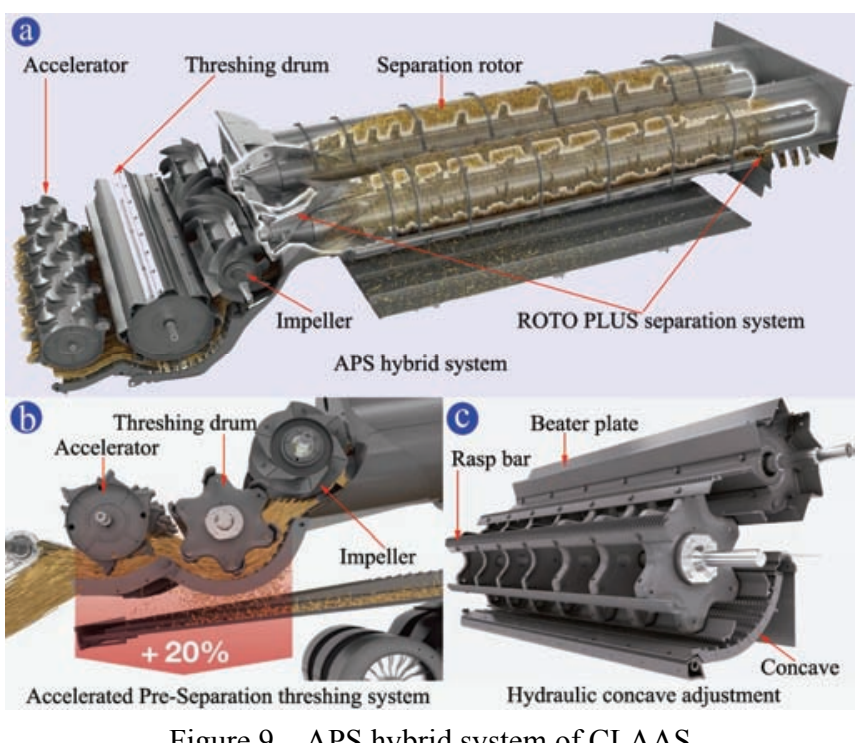

Figure 9 APS hybrid system of CLAAS

\subsubsection{APS of CLAAS}

Grain harvesters of CLAAS in Germany have a distinct competitive edge based on their APS hybrid system, which includes Accelerated Pre-Separation threshing system (APS) and ROTO PLUS separation system (Figure 9a). Three rolls are positioned in the APS threshing system, namely, accelerator, threshing drum and impeller (Figure 9b). Initial grain materials are accelerated from $3 \mathrm{~m} / \mathrm{s}$ to $20 \mathrm{~m} / \mathrm{s}$ by the accelerator. As well as $30 \%$ grain kernels are detached from the stem by the threshing drum. Simultaneously, grain materials threshed are forced into the ROTO PLUS separation system by the impeller. Thus there is a net performance increase of up to $20 \%$. Six rasp bars are mounted on the threshing drum. A hydraulic concave adjustment is applied in Claas harvester (Figure 9c). The concave below the threshing drum is designed as a multi-crop concave with individual segments that can be changed easily. The concave gap could be 
adjusted conveniently. Consequently, grain loss and damage could be controlled.

\subsubsection{Diverse threshing system of Agco}

Agco in USA offers a more comprehensive range of machines and equipment, because there are five brands in this agricultural machinery company. Challenger, Gleaner, and Fendt has typical threshing system respectively (Figure 10). The longitudinal axial threshing technology has been applied on twin rotors, tine rotors and bullet rotors. However, the threshing rotor of Challenger is characterized by structure and size (Figure 10a). For example, the rotor is divided into two pieces of cylinder, namely small cylinder and large cylinder. Inlet auger is welded around the small cylinder. Two kinds of cylinder bars are bolted on the large cylinder. The main cylinder bar is rasp bar, and the additional cylinder bar is rubber plate. In addition, the length of the rotor is up to $3556 \mathrm{~mm}$, which increases crop throughout and allows combine to maximize productivity. The inlet auger could minimize grain damage, and the rasp bar could rub the crop multiple times to reduce grain losses.

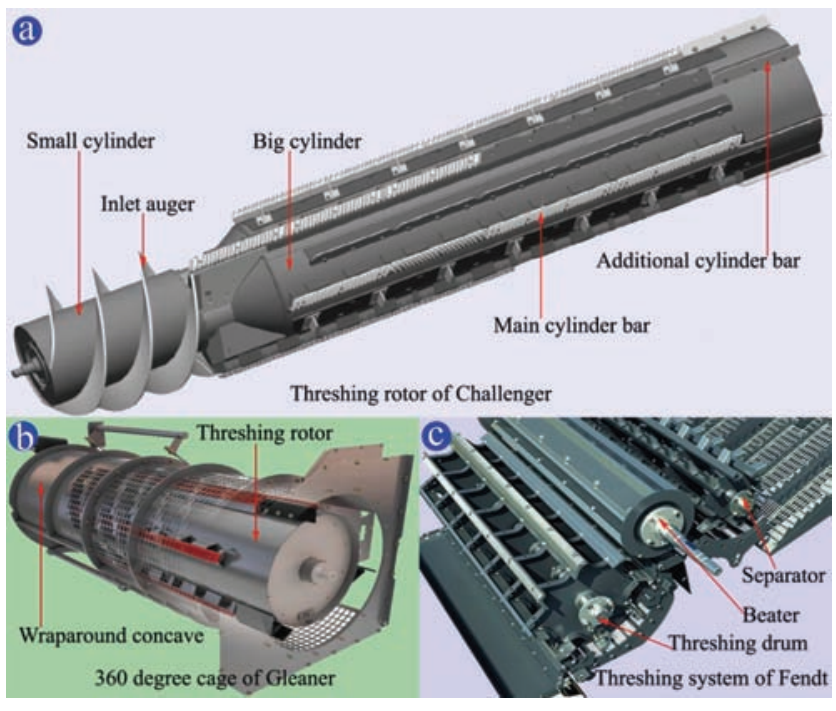

Figure 10 Threshing system of Agco

The threshing equipment of Gleaner consists of wraparound concave and threshing rotor (Figure 10b). Six rasp bars bolted on the rotor are chromed and reversible in the threshing area. The wraparound concave is $360^{\circ}$ in wrap angle. It is crucial that grain kernels could be threshed long enough to release them from grain ears. In addition, the $360^{\circ}$ cage could separate grain kernels once they are threshed. Thus, the wraparound concave could reduce grain loss and damage.

The threshing system of Fendt applies cross-tangential threshing technology. There are three rolls in the system (Figure 10c). Six rasp bars are bolted on the threshing drum. A beater roll is mounted rear the threshing drum to prevent grain straw blockage. The separator roll plays a significant role in increasing output, especially under difficult harvesting conditions, such as with green or damp straw.

\subsubsection{T-series and S-series of John Deere}

There are two major series of grain harvesters of John Deere in USA, namely T-series and S-series (Figure 11). T-series combine harvester of John Deere adopts cross-tangential threshing technology. There are four types of roller in the T-series threshing system (Figure 11a). The first roller is threshing cylinder with ten rasp bars. Its diameter is $660 \mathrm{~mm}$. It provides excellent grain quality and gentle material handing. A concave with wrapping angle of $124^{\circ}$ is installed below the threshing cylinder. It ensures threshing efficiency. The overshoot beater mounted behind the threshing cylinder could gently direct grain material to separator drum. This prevents material from back feeding on the threshing cylinder, eliminating blockages of the cylinder. Its diameter is $500 \mathrm{~mm}$, and its speed runs at 125 percent ratio of threshing cylinder speed. The separator drum separates the remaining grains out of the straw mat. Its diameter is $800 \mathrm{~mm}$, and its speed is $760 \mathrm{r} / \mathrm{min}$ for small grain such as wheat and rice. The rear beater continues the material flow process. It delivers material to the straw walkers with speed of $900 \mathrm{r} / \mathrm{mim}$ for small grain.

S-series combine harvester of John Deere adopts longitudinal axial threshing technology. The TriStream rotor is unique to John Deere, because it features a slightly tapered design in the threshing area (Figure $11 \mathrm{~b}$ ). The bullet-shaped rotor significantly reduces grain kernels damage coming from heavy rotor loads ${ }^{[98]}$. Furthermore, it could reduce the force required to move material through the rotor by as much as 20 percent. Two spiral accelerator vanes are installed at the tapered end of rotor. It improves material flow to feed into threshing system. The threshing element is designed for coarse grains and easy threshing small grains such as wheat and rice. Four ribs are obliquely distributed on the back surface of each threshing element. Consequently, rifling grooves are formed on the functional surface to enhance threshing performance (Figure 11c). There are fifteen threshing elements spiral around the TriStream rotor, which are cast-constructed and coated to improve 25 percent harder than chrome. Nine or twelve separator tines are bolted on the rotor. They are used to increase the dense material flow through the rotor, and to avoid blockage.

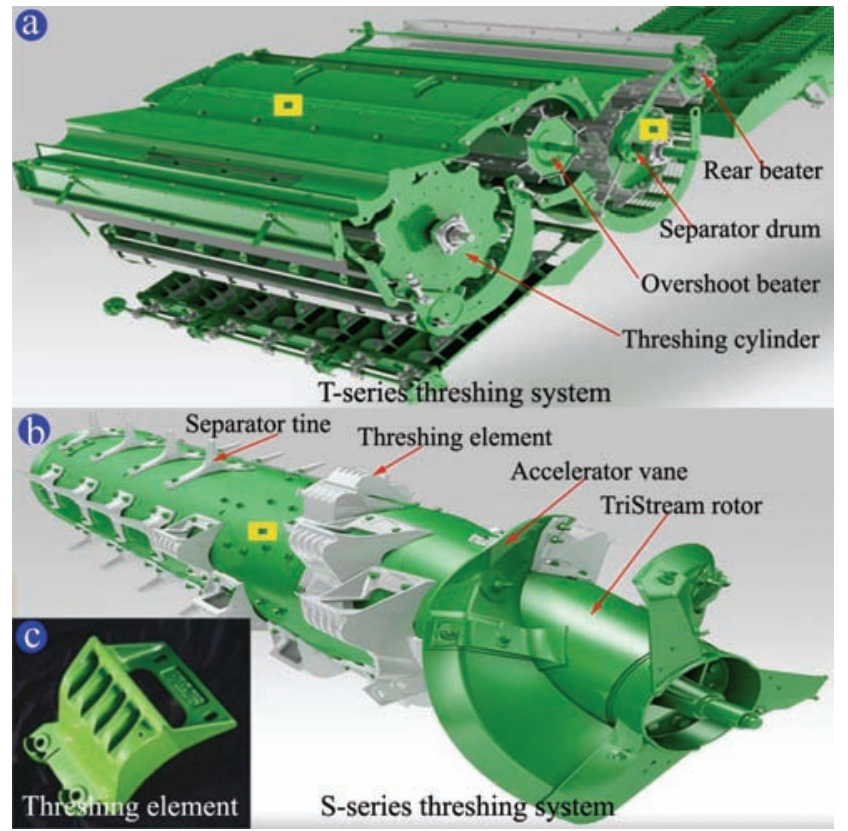

Figure 11 Threshing system of John Deere

\subsubsection{Axial-Flow of CASE IH}

The first axial-flow grain harvester was launched in 1977 by CASE IH. It is the unique single-rotor threshing equipment in the world and still sets the standard for harvesting performance today. Crop flow around the rotor is threshed efficiently. A transition cone is positioned in front of the Axial-Flow rotor (Figure 12). Vanes inside the cone sweep crop from the feeder and gently accelerated it to threshing speed. The Axial-Flow rotor consists 
of feeding vane, threshing element and rotor. This type of construction is popular with most agricultural machinery enterprises. The feeding vanes are bolted on the taper rotor. And the threshing elements are spirally installed around the cylinder rotor. Concentric rotor cage and wrap are positioned outside the Axial-Flow rotor respectively. Concentric rotor cage provides positive crop control and is perforated to allow $360^{\circ}$ maximum crop separation. The adjustable rotor vanes provide the ability to control crop flow by changing directions. There are two kinds of wrap below the Axial-Flow rotor. One is concave wrap of $156^{\circ}$, and it is designed in one piece. The other is module wrap of $180^{\circ}$, and is designed in two pieces. The two kinds of wrap are used in 140 series and 240 series combines respectively.

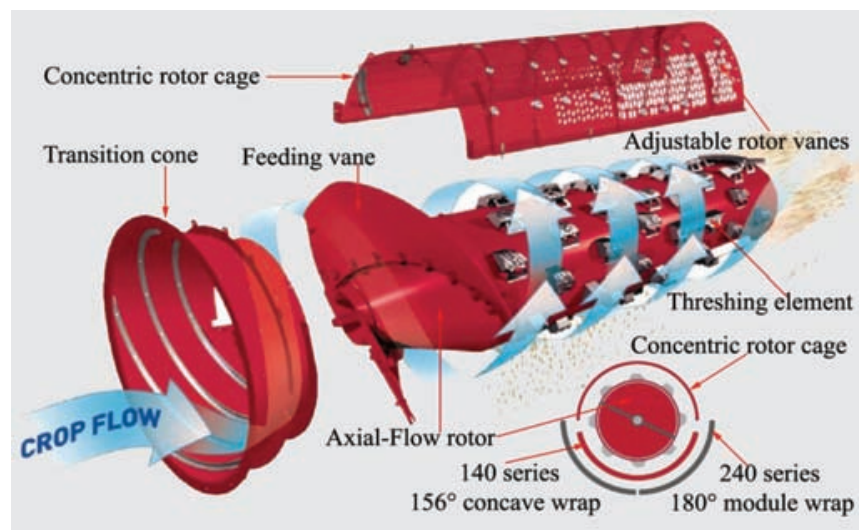

Figure 12 Threshing system of Case IH'

\subsubsection{Twin rotor and Four drum of New Holland}

There are two major types of grain threshing equipment in New Holland, namely twin rotor and four drum (Figure 13). The twin rotor threshing equipment adopts longitudinal axial threshing technology, and they are installed in CR series. The four drum threshing equipment adopts cross-tangential threshing technology, and they are mounted in CX series.

The twin rotor concept was invented by New Holland over 40 years ago (Figure 13a). It can significantly offer up to a 10 percent increase in threshing throughout. Two pitch rotors rotate reversely, and they are particularly suitable for damp conditions. About 44 threshing elements are installed on each rotor spirally (Figure 13b). A long concave is below each rotor, which enhances threshing performance. A dynamic feed roll is located in front of the twin rotors. It could speed up crop streamlined feeding, and improve feeder performance by up to 15 percent. In addition, a straw flow beater is located rear the twin rotors. Its diameter is $400 \mathrm{~mm}$, and it could move straw rearwards to improve grain throughout.

Grain harvesters of New Holland are popular for the four drum threshing equipment, which includes threshing drum, beater, rotary separator and straw flow beater(Figure 13c). The threshing drum installed rasp bars with a concave underneath the drum. Long blades are installed on the beater to force grain straw move rearwards, avoiding grain straw in rotary separator moving into threshing drum. The rotary separator consists of an open drum and fingers to accelerate grain kernels separating from straw. The straw flow beater is positioned on the back of the top of the rotary separator to enhance grain throughout. An opti-thresh system is adopted by New Holland (Figure 13d). It could adjust the wrap degree of concave (Figure 13e). According to grain maturity and yield, the rubbing action is changed by the opti-thresh system.

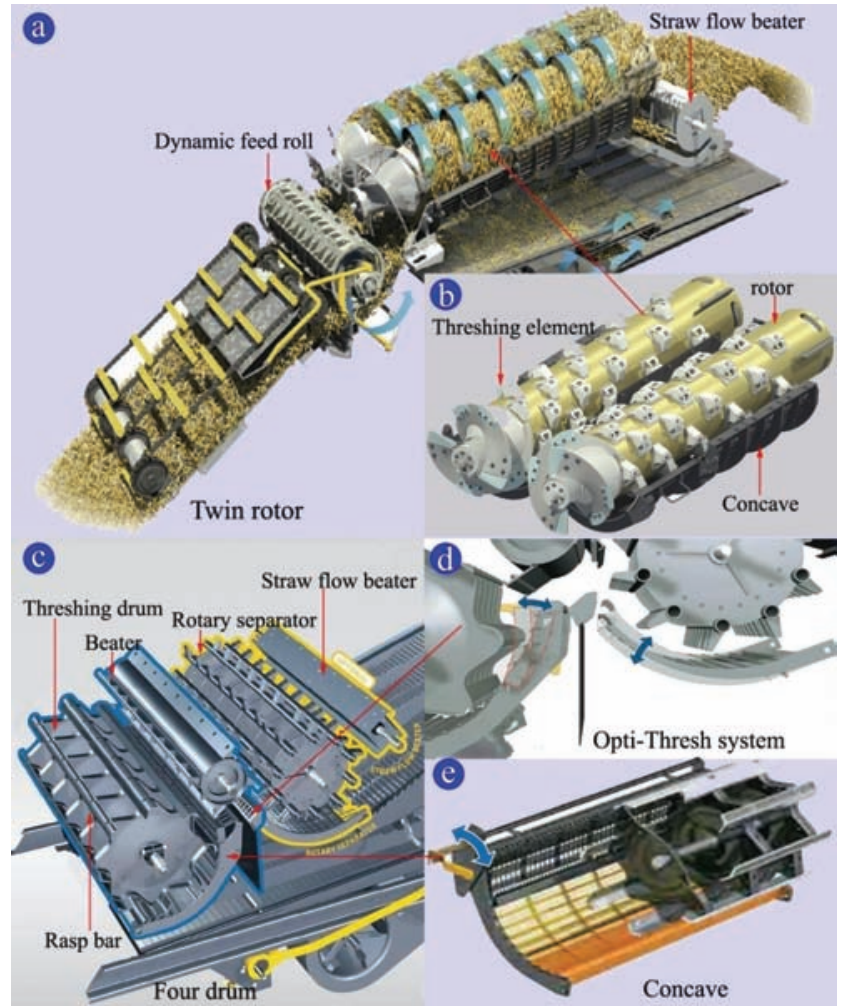

Figure 13 Threshing system of New Holland

\section{Development trend of grain threshing}

By reviewing the developments of principal technology and equipment of grain threshing, it is found that grain loss and damage are always the major evaluation indexes of threshing performance. The new trends of grain threshing are as follows.

Firstly, conical concave with continuous variable threshing clearance should be developed. The current threshing clearance between concave and threshing drum is fixed. However, the thickness of grain material flow decreases gradually when kernels detached from grain straw ${ }^{[99]}$. Consequently, the residual grain material in threshing gap is hard to be rubbed or impacted, and grain loss is still generated. In order to improve threshing quality, rotate speed of threshing drum is usually improved. But grain damage is significantly increased as the bigger momentum. So, it is necessary to develop a conical concave, which could produce a continuous variable clearance. At the front-end of the conical concave, the inlet of grain material is formed, and the threshing clearance is largest. Likewise, in the back-end of the conical concave, the outlet is generated, and the threshing clearance is least Obviously, grain material could be threshed efficiently with low loss and damage based on the conical concave. So, the conical concave may take the place of the traditional cylindrical one.

Secondly, multifunctional axial threshing rotor will be popular with farmers. With the development of longitudinal axial threshing technology, diverse axial threshing rotors have been innovated all the time. However, different grain crop needs diverse threshing rotor; especially different moisture content and feed quantity of one-grain crop demands different parameters of a threshing rotor. So, it is necessary to design a multifunctional axial threshing rotor, for example, make rasp bar, bow tooth and spike tooth distribute on different sections of a long axial threshing rotor. Consequently, there are multiple functional areas on the axial rotor. Grain material is first threshed by rasp bars, then by bow teeth, and finally by spike teeth. Grain loss and damage 
could be increased by adjusting distribution of threshing element on rotor.

Thirdly, intelligent harvesting robot will become the best control tool for performance. There are a number of performance factors for grain harvester, such as line of precision, feed quantity, moisture content, rotating speed and contact gap. These factors require real-time and accurate coordination to achieve optimal performance. Sensor and information communication technology integrated in intelligent harvesting robot could provide the best solution $^{[100-102]}$. A computer program written in Visual Basic could be used to select optimum operating performance in grain crop thresher. Global navigation satellite system (GNSS), GPS compass, and laser range finder (LRF) could be installed on the combine harvester, and a three-dimensional (3D) map could be generated and then converted into a top-view image. Consequently, grain flow could be pinpointed. In addition, piezoelectric sensor could be used to detect grain loss. Infrared sensor could analyze grain damage. Ultrasonic wave sensor, vibrating sensor and laser sensor could be used to optimize motion parameters of grain harvester. Hence, sensor is the key component to collect data, and control module is the intelligent accessory to analyze data. Based on the two accessory devices, farmers could conveniently change parameter of threshing system. For example, when the loss data is collected by sensor, farmers could control the threshing clearance by electromagnetic sensor in cab. So, automation and intelligentization could reduce labor strength and raise threshing quality.

\section{Conclusions and recommendations}

1) Threshing interface is the fundamental theory of techniques and equipment. It consists of two contact surfaces of grain ear and threshing component. Four types of contact models explain threshing principles accurately. Based on threshing interface, influence factors of grain loss and damage could be defined. Impacting and rubbing contact models are all established based on rotational motion. Speed and clearance are major factors of threshing stress. Moisture content and grain thickness are major factors of material properties. Design of threshing component and parameter of threshing equipment should take account of stress and material. Consequently, grain loss and damage could be controlled effectively.

2) Tangential and axial threshing technologies are applied in grain threshing system widely. T-series of John Deere, Four drums of New Holland and Fendt of Agco apply tangential threshing technology on threshing drum independently. While S-series of John, Twin rotor of New Holland, APS of CLAAS, Axial-Flow of CASE IH, Challenger and Gleaner of AGCO apply tangential and axial threshing technologies together. It shows that in the combined application, tangential rolls are used to accelerate grain flow, and axial rolls are used to raise threshing quality especially lower loss and damage.

3) Intelligent threshing system may be the best solution for threshing quality. Grain loss and damage come from mechanical action of threshing. Framers in cab are hard to adjust operational parameter of grain harvester timely. In addition, material properties such as moisture content and planting density are diverse. So, speed and clearance of threshing system should be controlled intelligently. With the development of sensor and hydromantic, intelligent control system and mechanical threshing system will mix together to improve grain quality and operation comfort.

\section{Acknowledgements}

This work was supported by the National Natural Science Foundation of China (51705193), National Key Research and Development Project (2017YFD0700302) and the Science and Technology Development Project of Jilin Province (20170204016NY).

\section{[References]}

[1] Li Z, Liu Z, Anderson W. Chinese rice production area adaptations to climate changes, 1949-2010. Environmental Science and Technology; 2015; 49(4): 2032-2037. (in Chinese)

[2] Callaway E. Domestication: The birth of rice. Nature, 2014; 514(7524): 58-59.

[3] Gobbett D L, Hochman Z, Horan H. Yield gap analysis of rainfed whea demonstrates local to global relevance. The Journal of Agricultural Science, 2017; 155(2): 282-299.

[4] Wu Q, Xia G M, Chen T T, Chi D C, Jin Y, Sun D H. Impacts of nitrogen and zeolite managements on yield and physicochemical properties of rice grain. Int J Agric \& Biol Eng, 2016; 9(5): 93-100.

[5] Cerquitelli T. Predicting large scale fine grain energy consumption. Energy Procedia, 2017; 111: 1079-1088.

[6] Zami M A, Hossain M A, Sayed M A, Biswas B K, Hossain M A. Performance Evaluation of the BRRI Reaper and Chinese Reaper Compared to Manual Harvesting of Rice (Oryza sativa L.). The Agriculturists, 2015; 12(2): 142-150.

[7] Unakitan G, Aydin B. A comparison of energy use efficiency and economic analysis of wheat and sunflower production in Turkey: A case study in Thrace Region. Energy, 2018; 149: 279-285.

[8] Hanna H M, Quick G R. Grain harvesting machinery. Handbook of Farm, Dairy and Food Machinery Engineering, Academic Press, 2013; pp.223-257.

[9] Alizadeh M R, Bagheri I. Field performance evaluation of different rice threshing methods. International Journal of Natural and Engineering Sciences, 2009; 3(3): 139-143.

[10] Zareiforoush H, Komarizadeh M H, Alizadeh M R. Effects of crop-machine variables on paddy grain damage during handling with an inclined screw auger. Biosystems Engineering, 2010; 106(3): 234-242.

[11] Khir R, Atungulu G, Ding C, Pan Z L. Influences of harvester and weather conditions on field loss and milling quality of rough rice. Int $\mathrm{J}$ Agric \& Biol Eng, 2017; 10(4): 216-223.

[12] Špokas L, Steponavičius D, Petkevičius S. Impact of technological parameters of threshing apparatus on grain damage. Agronomy Research, 2008; 6: 367-376.

[13] Gbabo A, Gana I M, Amoto M S. Design, fabrication and testing of a millet thresher. Net Journal of Agricultural Science, 2013; 1(4): 100-106.

[14] Singh B, Linvill D E. Determining the effect of pod and grain moisture content on threshing loss and damage of navy beans. Transaction of the ASAE, 1977; 2: 226-231.

[15] Ndirika V I O. A mathematical model for predicting output capacity of selected stationary grain threshers. Agricultural Mechanization in Asia, Africa, and Latin America, 2005; 36(2): 9-13.

[16] Wang G, Jia H L, Tang L, Zhuang J, Jiang X X. Design of variable screw pitch rib snapping roller and residue cutter for corn harvesters. Int $\mathrm{J}$ Agric \& Biol Eng, 2016; 9(1): 27-34.

[17] Li H C, Li Y Y, Gao F, Zhao Z, Xu L Z. CFD-DEM simulation of material motion in air-and-screen cleaning device. Computers and Electronics in Agriculture.2012; 88: 111-119.

[18] Yang L, Cui T, Qu Z, Zhang D X. Development and application of mechanized maize harvesters. Int J Agric \& Biol Eng, 2016; 9(3): 15-28.

[19] Nawrocka A, Stępień E, Grundas S, Nawrot Jan. Mass loss determination of wheat kernels infested by granary weevil from X-ray images. Journal of Stored Products Research, 2012; 48: 19-24.

[20] Karlen D L, Birrell S J, Johnson J M F, Osborne S L, Schumacher T E, Varvel G E. Multilocation corn stover harvest effects on crop yields and nutrient removal. Bio Energy Research, 2014; 7(2): 528-539.

[21] Markowski M, Żuk-Gołaszewska K, Kwiatkowski D. Influence of variety on selected physical and mechanical properties of wheat. Industrial Crops and Products, 2013; 47: 113-117.

[22] Huynh V M, Powell T, Siddall J N. Threshing and separating process-A mathematical model. Transaction of the ASAE.1982; 25(1): 65-73.

[23] Abdi R, Jalali A. Mathematical model for prediction combine harvester 
header losses. International Journal of Agriculture and Crop Sciences, 2013; 5(5): 549-556.

[24] Pishgar-Komleh S H, Keyhani A, Mostofi-Sarkari M R, Jafari A. Assessment and determination of seed corn combine harvesting losses and energy consumption. Elixir Agriculture, 2013; 54: 12631-12637.

[25] Audilakshmi, Aruna S C, Solunke R B, Kamatar M Y, Kandalkar H G, Gaikwad P. Approaches to grain quality improvement in rainy season sorghum in India. Crop Protection, 2007; 26: 630-641.

[26] Baryeh E A. A simple grain impact damage assessment device for developing countries. Journal of Food Engineering, 2003; 56: 37-42.

[27] Mirzazadeh A, Abdollahpour S, Mahmoudi A, Bukat A R. Intelligent modeling of material separation in combine harvester's thresher by ANN. International Journal of Agriculture and Crop Sciences, 2012; 4(23): 1767-1777.

[28] Behnke W, Brune M. Method for controlling a crop separating process of a combine harvester: U.S. Patent 8,676,453. 2014-3-18.

[29] Khazaei J, Shahbazi F, Massah J. Evaluation and modeling of physical and physiological damage to wheat seeds under successive impact loadings: mathematical and neural networks modeling. Crop Science, 2008; 48(4): $1532-1544$.

[30] Harrison H P. Grain separation and damage of an axial flow combine. Canadian Agricultural Engineering, 1992; 34(1): 49-53.

[31] Lashgari M, Mobli H, Omid M. Qualitative analysis of wheat grain damage during harvesting with John Deere combine harvester. International Journal of Agriculture and Biology, 2008; 10: 201-204.

[32] Kalkan F, Kara M, Bastaban S, Turgut N. Strength and frictional properties of popcorn kernel as affected by moisture content. International Journal of Food Properties, 2011; 14(6): 1197-1207.

[33] Agelet L E, Ellis D D, Duvick S, Goggi A S, Hurburgh C R, Gardner C A. Feasibility of near infrared spectroscopy for analyzing corn kernel damage and viability of soybean and corn kernels. Journal of Cereal Science, 2012; 55(2): 160-165.

[34] Shahbazi F. A study on the seed susceptibility of wheat (Triticum aestivum L.) cultivars to impact damage. Journal of Agricultural Science and Technology, 2012; 14(3): 505-512.

[35] Zhu M, Shabala S, Shabala L, Fan Y, Zhou M X. Evaluating predictive values of various physiological indices for salinity stress tolerance in wheat. Journal of Agronomy and Crop Science, 2016; 202(2): 115-124.

[36] Delwiche S R, Yang I C, Graybosch R A. Multiple view image analysis of freefalling U.S. wheat grains for damage assessment. Computers and Electronics in Agriculture, 2013; 98: 62-73.

[37] Delwiche S R, Kim M S, Dong Y. Fusarium damage assessment in wheat kernels by Vis/NIR hyperspectral imaging. Sensing and Instrumentation for Food Quality and Safety, 2011; 5(2): 63-71.

[38] Miller J D. Fungi and mycotoxins in grain: implications for stored product research. Journal of Stored Products Research, 1995; 31(1): $1-16$.

[39] Singh C B, Jayas D S, Paliwal J, White N D. Fungal damage detection in wheat using short-wave near-infrared hyperspectral and digital colour imaging. International Journal of Food Properties, 2012; 15(1): 11-24.

[40] Herrera J M, Pizzolitto R P, Zunino M P, Dambolena J S, Zygadlo J A. Effect of fungal volatile organic compounds on a fungus and an insect that damage stored maize. Journal of Stored Products Research, 2015; 62: $74-80$.

[41] Zhou Q, Ravnskov S, Jiang D, Wollenweber B. Changes in carbon and nitrogen allocation, growth and grain yield induced by arbuscular mycorrhizal fungi in wheat (Triticum aestivum L.) subjected to a period of water deficit. Plant Growth Regulation, 2015; 75(3): 751-760.

[42] Baktash F Y, Alkazaali H A. Effect of grain moisture of corn at harvesting on some agronomic traits. The Iraqi Journal of Agricultural Sciences, 2016; 47(5): 1334-1339.

[43] Ahmad S A, Iqbal M, Ahmad M, Tanveer A, Sial J K. Design improvement of indigenous beater wheat thresher in pakistan. Pakistan Journalof Agricultural Sciences, 2013; 50: 711-721.

[44] Mesquita C, Hanna M, Costa N, França N. Soya bean threshing by nylon cords on rotating shafts. Journal of Agricultural Engineering Research, 2000; 77(3): 297-301.

[45] Kalsirisilp R, Singh G.. Adoption of a stripper header for a Thai-made rice combine harvester. Journal of Agricultural Engineering Research, 2001; 80: 163-172.

[46] Sudajan S, Salokhe V M, Chusilp S. Effect of concave hole size, concave clearance and drum speed on rasp-bar drum performance for threshing sunflower. Agricultural Mechanization in Asia, Africa, and Latin
America, 2005; 36: 52-60.

[47] Kemanian A R, Stöckle C O, Huggins D R, Viega L M. A simple method to estimate harvest index in grain crops. Field Crops Research, 2007; 103(3): 208-216.

[48] Yang L, Cui T, Qu Z, Zhang D X. Development and application of mechanized maize harvesters. Int J Agric \& Biol Eng, 2016; 9(3): 15-28.

[49] Gregory J M. Combine model for grain threshing. Mathematicaland Computer Modelling, 1988; 11: 506-509.

[50] Wang X R, Shi Q X, Ni C N. Study on the impact numbers of threshing tooth on rice grain for semi feeding unit. Journal of Agricultural Mechanization Research, 2011; 4: 17-20. (in Chinese)

[51] Olaoye J O, Oni K C, Olaoye M M. Computer applications for selecting operating parameters of stationary grain crop thresher. Int J Agric \& Biol Eng, 2010; 3(3): 8-18.

[52] Xu L Z, Li Y M, Ding L F. Contacting mechanics analysis during impact process between rice and threshing component. Transactions of the CSAE, 2008; 24(6): 146-149. (in Chinese)

[53] Li Y M, Wang X R, Xu L Z. Thresing injury to rice grain based on thre energy conservation. Chinese Journal of Mechanical Engineering, 2007; 43(3): 160-164. (in Chinese)

[54] Xu L Z, Li Y M, Li H C. Analysis on factors affecting performance of rice kernel damage during threshing. Transactions of the CSAM, 2008; 39(12): 55-59. (in Chinese)

[55] Liang Z, Li Y, Xu L, Zhao Z, Tang Z. Optimum design of an array structure for the grain loss sensor to upgrade its resolution for harvesting rice in a combine harvester. Biosystems Engineering, 2017; 157: 24-34.

[56] Alluvione F, Moretti B, Sacco D, Grignani C. EUE (energy use efficiency) of cropping systems for a sustainable agriculture. Energy, 2011; 36(7): 4468-4481.

[57] Xu L Z, Li Y M, Ma Z, Zhao Z, Wang C H. Theoretical analysis and finite element simulation of a rice kernel obliquely impacted by a threshing tooth. Biosystems Engineering, 2013; 114: 146-156.

[58] $\mathrm{Xu} \mathrm{L} \mathrm{Z,} \mathrm{Li} \mathrm{Y} \mathrm{M.} \mathrm{Finite} \mathrm{element} \mathrm{analysis} \mathrm{on} \mathrm{damage} \mathrm{of} \mathrm{rice} \mathrm{kernel}$ impacting on spike tooth. Transactions of the CSAE, 2011; 27(10): 27-32. (in Chinese)

[59] Yu Y, Fu H, Yu J. DEM-based simulation of the corn threshing process. Advanced Powder Technology, 2015; 26(5): 1400-1409.

[60] Tang Z, Li Y, Xu L, Kumi F. Modeling and design of a combined transverse and axial flow threshing unit for rice harvesters. Spanish Journal of Agricultural Research, 2014; 12(4): 973-983.

[61] Špokas L, Steponavičius D. Impact of wheat stubble height on combine technological parameters. Journal of Food, Agriculture and Environmental, 2010; 8(2): 464-468.

[62] Dhananchezhiyan P, Parveen S, Pandian S. Development and comparative study of cast Iron rasp bar and nylon rasp bar threshing cylinders for paddy threshing. Agricultural Engineering, 2013; 4: 45-54.

[63] Pužauskas E, Steponavičius D, Jotautienė E, Kemzūraitė, A. Substantiation of concave crossbar shape for corn ear threshing. Mechanics, 2016; 22(6): 553-561.

[64] Dhananchezhiyan P, Parveen S, Rangasamy K, Rangasamy K, Shridar B, Kumar A S. Development of a Nylon Rasp Bar Threshing Cylinder for Portable Paddy Thresher and its Performance Evaluation. Madras Agricultural Journal, 2013; 100: 623-626.

[65] Xu L Z, Li Y M. Modeling and experiment to threshing unit of stripper combine. African Journal of Biotechnology, 2011; 10(20): 4106-4113.

[66] Osueke C O. Frictional impact modeling of a cereal thresher. Am. J. Engg. \& Applied Sci, 2011; 4(3): 405-412.

[67] Olaoye J O, Oni K C, Olaoye M O. Computer applications for selecting operating parameters in a stationary grain crop thresher. Journal of Agricultural Technology, 2011; 7(1): 39-56.

[68] Maertens K, Baerdemaeker J D. Design of a virtual combine harvester. Mathematics and Computersin Simulation, 2004; 65: 49-57.

[69] Li H, Wang J S, Yuan J B, Qian Y Z. Analysis of rice mixture separation through vibration screen using discrete element method. Int J Agric \& Biol Eng, 2017; 10(11): 231-239.

[70] Miu P I, Kutzbach H D. Mathematical model of material kinematics in an axial threshing unit. Computers and Electronics in Agriculture, 2007; 58: 93-99.

[71] Miu P I, Kutzbach H D. Modeling and simulation of grain threshing and separation in threshing units-Part I. Computers and Electronics in Agriculture, 2008; 60: 96-104.

[72] Li Y M, Li H C, Xu L Z. Comparative experiments on threshing performance between short-rasp-bar tooth cylinder and spike tooth 
cylinder. Transactions of the CSAE, 2008; 24(3): 139-142. (in Chinese)

[73] Jiang Y Y, Tu C H, Xu J M. A rice harvesting machine system for threshing prior to cutting. Transactions of the CSAE, 1993; 24(1): 55-60. (in Chinese)

[74] Evers T, Millar S. Cereal grain structure and development: some implications for quality. Journal of Cereal Science, 2002; 36(3): 261-284.

[75] Neale M A, Hobson R N, Price J S, Bruce D M. Effectiveness of three types of grain separator for crop matter harvested with a stripping header. Biosystems Engineering, 2003; 84: 177-191.

[76] Shahbazi F. Impact damage to chickpea seeds as affected by moisture content and impact velocity. Applied Engineering in Agriculture, 2011; 27(5): 771-775.

[77] Shahbazi F, Saffar A, Analooei M. Mechanical damage to navy beans as affected by moisture content, impact velocity and seed orientation. Quality Assurance and Safety of Crops \& Foods, 2011; 3(4): 205-211.

[78] Shahbazi F, Analooei M, Saffar A. Mechanical damage to pinto bean seeds as affected by moisture content, impact velocity and seed orientation. International Journal of Food Engineering 2011; 7(6): 1-15.

[79] Langa F P, Muiru W M, Mbuge D, Ragwa, L R, Olubayo F M, Muthomi J W. Influence of endosperm types, seed moisture content and threshing methods on germination and seedling vigour of sorghum. World Journal of Agricultural Sciences 2016; 12(5): 378-383.

[80] Špokas L, Steponavičius D, Butkus V, Kiniulis V. Substantiation of the Rational Technological Parameters for Threshing High-moisture Corn Ears. Rural Development, 2013; 6(1): 139-146.

[81] Al-Mahasneh M A, Rababah T M. Effect of moisture content on some physical properties of green wheat. Journal of Food Engineering, 2007; 79: $1467-1473$

[82] Woźniak W, Styk W. Internal damage to wheat grain as a result of wetting and drying. Drying Technology, 1996; 14(2): 349-365.

[83] Govindaraj M, Masilamani P, Asokan D, Selvaraju P. Effect of Different Harvesting and Threshing Methods on Seed Quality of Rice Varieties. Int. J. Curr. Microbiol. Appl. Sci., 2017; 6: 2375-2383.

[84] Boyd R S, Lauwers A V, Farley H M. Combine crop conveying and feeding system. 2016; U.S. Patents No.9301450.

[85] Chuan-udom S, Chinsuwan W. Effects of operating factors of an axial flow rice combine harvester on grain breakage. Sonklanakarin Journal of Science and Technology, 2011; 33(2): 221-225.

[86] Ahmadian H, Hassanpour A, Ghadiri M. Analysis of granule breakage in a rotary mixing drum: experimental study and distinct element analysis. Powder Technology, 2011; 210(2): 175-180.

[87] Maertens K, De Baerdemaeker J. Flow rate based prediction of threshing process in combine harvesters. Applied Engineering in Agriculture, 2003; 19(4): 383-388.

[88] Radwan G G, Salim R G, Al-Ashry A S. Development and test attachments to the tangential flow thresher to suit caraway crop threshing. Misr Journal of Agricultural Engineering, 2009; 26(3): 1068-1080.
[89] Osueke E C O. Study of the influence of crop, machine and operating parameters on performance of cereal threshers. International Journal of Engineering Research and Development, 2014; 7: 1-9.

[90] Sambasivan S, Kapahi A, Udaykumar H. Simulation of high speed impact, penetration and fragmentation problems on locally refined Cartesian grids. Journal of Computational Physics, 2013; 235: 334-370.

[91] Zhao Z, Li Y M, Liang Z W, Gong Z Q. DEM simulation and physical testing of rice seed impact against a grain loss sensor. Biosystems Engineering, 2013; 116: 410-419.

[92] Lenaerts B, Aertsen T, Tijskens E, Ketelaere B D, Ramon H, Baeraemaeker J D. Simulation of grain-straw separation by discrete element modeling with bendable straw particles. Computers and Electronics in Agriculture, 2014; 101: 24-33.

[93] Ma J. An innovative vertical axial-flow threshing machine developed in China. Agricultural Mechanization in Asia, Africa, and Latin America, 2007; 38: 18-22.

[94] Ma J. Analysis of performance and architechtural feature of threshing parts of vertical axial flow. Agricultural Machinery, 2003; 02: 24-26. (in Chinese)

[95] Craessaerts G, Saeys W, Missotten B, Baerdemaeker J D. A genetic input selection methodology for identification of the cleaning process on a combine harvester, Part I: selection of relevant input variables for identification of the sieve losses. Biosystems Engineering, 2007; 98: 166-175.

[96] Tado C, Wacker P, Kutzbach H. Development of stripper harvesters: a review. Journal of Agricultural Engineering Research, 1998; 71: $103-112$.

[97] Jiang Y Y, Tu C H, Luo P Z, Xu J M, Liu D S. Experimental investigation on TPC threshing apparatus of the drum type with wire loops. Journal of Northeast Agricultural College, 1988; 19(3): 320-328. (in Chinese)

[98] Zareiforoush H, Komarizadeh M H, Alizadeh M R. Effects of crop-machine variables on paddy grain damage during handling with an inclined screw auger. Biosystems Engineering, 2010; 106: 234-42.

[99] Zhao Z, Li Y M, Chen J, Xu J. Grain separation loss monitoring system in combine harvester. Computers and Electronics in Agriculture, 2011; 76: $183-188$.

[100] Wang H, Hu J T, Gao L, Jia Y F. Development and optimization of a novel grain flow sensor based on PVDF piezoelectric film. Int J Agric \& Biol Eng, 2016; 9(4): 141-150.

[101] Cho W, Kurita H, Iida M, Masuda R. Autonomous positioning of the unloading auger of a combine harvester by a laser sensor and GNSS. Engineering in Agriculture, Environment and Food, 2015; 8(3): 178-186.

[102] Cho W, Iida M, Suguri M, Masuda R, Kurita H. Using multiple sensors to detect uncut crop edges for autonomous guidance systems of head-feeding combine harvesters. Engineering in Agriculture, Environment and Food, 2014; 7(3): 115-121. 